\title{
Fatigue growth of a surface crack in a V-shaped notched round bar under cyclic tension"
}

\author{
Devi CHANDRA ${ }^{1,3}$, Judha PURBOLAKSONO ${ }^{\dagger 1}$, Yusoff NUKMAN ${ }^{2}$, \\ Haw-ling LIEW ${ }^{1}$, Singh RAMESH ${ }^{1}$, Mohsen-abdel HASSAN ${ }^{1}$ \\ $\left({ }^{1}\right.$ Center of Advanced Manufacturing and Materials Processing, Department of Mechanical Engineering, \\ Faculty of Engineering, University of Malaya, Kuala Lumpur 50603, Malaysia) \\ $\left({ }^{2}\right.$ Center of Manufacturing System Integration, Department of Mechanical Engineering, \\ Faculty of Engineering, University of Malaya, Kuala Lumpur 50603, Malaysia) \\ $\left({ }^{3}\right.$ Department of Mechanical Engineering, Faculty of Engineering, University of Andalas, Padang 25163, Indonesia) \\ †E-mail: judha@um.edu.my; judha.purbolaksono@gmail.com \\ Received Jan. 28, 2014; Revision accepted June 9, 2014; Crosschecked Oct. 30, 2014
}

\begin{abstract}
This paper presents modeling results for fatigue crack growths of a semi-elliptical surface crack in a V-shaped notched round bar under uniform cyclic tension. All the analyses were carried out by using a software package featuring the boundary element method. The $J$-integral technique was used to compute the stress intensity factors (SIFs), and the NASGRO crack growth rate was chosen to simulate the fatigue crack growths. Mechanical and fracture properties of AZ-6A-T5 magnesium alloy were used for our analysis. Crack shape evolutions for different crack aspect ratios and the corresponding SIFs may be correlated to study the behavior of crack growths. An unstable crack growth was observed when the evolving crack aspect ratio was between 0.6 and 0.7. Careful consideration should be taken if the cylinder contains a defect which has a straight shape on the crack front or a smaller crack aspect ratio.
\end{abstract}

Key words: Fatigue crack growth, Crack aspect ratio, Boundary element method, Stress intensity factor (SIF) doi: $10.1631 /$ jzus.A1400042

\section{Introduction}

Many engineering structures and mechanical components contain geometrical discontinuities like 'notch' such as shafts, bars, bolts, rivets, screws, and pins. During service, the notched components are often subjected to cyclic loading that can cause higher strain deformation at the notch root. Larger strain deformation may eventually lead to surface crack initiation. Then, the crack grows into a critical stage,

\footnotetext{
${ }^{\ddagger}$ Corresponding author

* Project supported by the Malaysian Ministry of Higher Education (MOHE) through the High Impact Research Grant (No. UM.C/625/1/ $\mathrm{HIR} / \mathrm{MOHE} / \mathrm{ENG} / 33$ )

C Zhejiang University and Springer-Verlag Berlin Heidelberg 2014
}

which can result in an undesirable fracture failure. According to the concept of damage tolerance analysis, the fatigue crack growth analysis requires an accurate life prediction to judge the component that needs to be fit for service.

The stress intensity factor (SIF) is an important parameter in assessment of cracked components. The calculation of an SIF is required to quantify the stress field in the vicinity of the crack tip. The SIF solutions for a surface crack in a smooth round bar under tension have been reported by many researchers. Raju et al. (1986) calculated the SIFs of a semi-elliptical crack using a 3D-finite element method (FEM). Carpinteri and Brighenti (1996) reported the fatigue crack growths using Paris's law for three different model parameters (ellipse aspect ratio, crack depth 
ratio, and ellipse shifting ratio). Shih and Chen (2002) used the ANSYS finite element analysis (FEA) software to evaluate the SIFs of an elliptical crack in a round bar by introducing collapsed singular elements. They also reported the close form solutions of the corresponding SIFs. Shin and Cai (2004) used the ABAQUS FEA codes and performed their experimentations to analyze the SIFs of a semielliptical surface crack in a rod for different crack aspect ratios.

Some studies on surface cracks in a notched cylinder have also been carried out. Lin and Smith (1998; 1999) investigated crack shape evolution, crack shape deviation, and variation of the aspect ratio of a surface crack in a semi-circular notched round bar. They utilized a linear elastic 3D-FEA to estimate SIFs along the crack front and used Paris's equation for simulating fatigue crack growths. Guo et al. (2003) studied the effects of the stress concentration coefficients $K_{t}$ and notch geometry on the SIFs of a semi-elliptical surface crack in notched round bars under tension load by using ANSYS FEA software. They also carried out evaluations of the SIFs of a semi-elliptical surface crack in various semi-circular types of V- and U-type annular notches. It was found that the SIFs are strongly dependent on $K_{t}$, and the influence of notch geometry on the SIFs can be neglected. Carpinteri et al. (2006) also used a 3D-FEM to compute and evaluate the SIFs and fatigue growth of an elliptical-arc surface crack in a notched round bar under cyclic tension and bending using the ParisErdogan law. A review of the results related to such a problem was presented by Carpinteri et al. (2013).

A quarter- or half-cracked model was used in most of the previous studies by the FEM. However, not many findings on fatigue growth of a surface crack in a solid cylinder have been reported. Most of the researches that have been reported were using the Paris's crack growth law for their simulations. In the present study, the fatigue crack growths, the SIFs, and the crack shape evolutions of a semi-elliptical surface crack in a full model of a V-shaped notched round bar under cyclic tension are evaluated using the boundary element method software package of BEASY (BEASY, 2013). The mechanical and fracture properties of AZ-6A-T5 magnesium alloy are used in the simulations. The $J$-integral is used to evaluate the SIFs, and the NASGRO crack growth rate law is chosen to simulate the fatigue crack growths. The influences of notch size and aspect ratios of cracks on the SIFs and fatigue life are studied.

\section{Simulation procedures}

\subsection{Model geometry and materials}

The model as shown in Fig. 1a is a circumferentially V-shaped notched round bar with an outer diameter $D=12.7 \mathrm{~mm}$, length $L=107.95 \mathrm{~mm}$, diameter of notch cross section $d=6.35 \mathrm{~mm}$, notch depth $t=3.175 \mathrm{~mm}$, notch opening angle equal to $60^{\circ}$, and a notch root radius $r=0.529 \mathrm{~mm}$ or $1.588 \mathrm{~mm}$. These geometries are similar to those used in (Zeng and Fatemi, 2001).

(a)

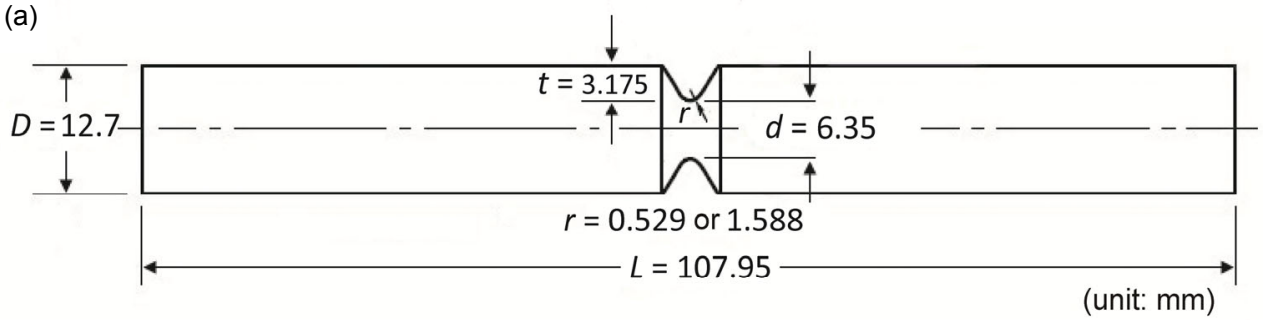

(b)

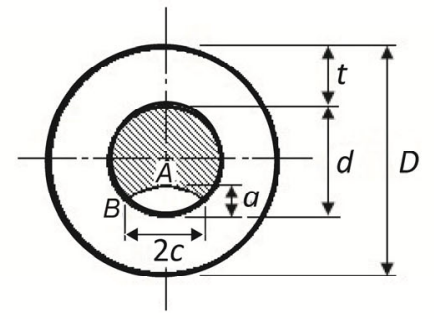

Fig. 1 The geometrical detail of the circumferentially $V$-shaped notched round bar model (a) and the surface crack (b) 
A semi-elliptical surface crack was introduced at the notch root. The crack plane was set to be normal to the axis of the round bar. The details of the crack depth $a$ and the crack length $c$ are depicted in Fig. 1b. Points $A$ and $B$ shown in Fig. 1b denote the depth point and the surface point on the crack front, respectively. Table 1 lists the mechanical and fracture properties of AZ-6A-T5 magnesium alloy that are used in the NASGRO equation.

The generalized NASGRO equation is widely used in many practical simulations. The equation incorporates the fatigue crack closure feature by considering the effect of the stress ratio on crack growth rate (Newman et al., 1994):

$$
\frac{\mathrm{d} a}{\mathrm{~d} N}=\frac{C(1-f)^{n} \Delta K^{n}\left(1-\frac{\Delta K_{\mathrm{th}}}{\Delta K}\right)^{p}}{(1-R)^{n}\left[1-\frac{\Delta K}{(1-R) K_{\mathrm{C}}}\right]^{q}},
$$

where $N$ is the fatigue loading cycles, $a$ is the crack length (crack depth), $R$ is the stress ratio, $\Delta K_{\text {th }}$ is the threshold SIF, $\Delta K$ is the range of SIFs, $K_{\mathrm{C}}$ is the plane stress fracture toughness, the constants $C, n, p$, and $q$ are the NASGRO coefficients, and $f$ is the crack opening function that is defined as (Newman et al., 1994)

$$
f=\left\{\begin{array}{l}
\max \left\{R, A_{0}+A_{1} R+A_{2} R^{2}+A_{3} R^{3}\right\}, \quad R \geq 0 \\
A_{0}+A_{1} R, \quad-2 \leq R<0,
\end{array}\right.
$$

Table 1 Mechanical and fracture properties of AZ-6AT5 magnesium alloy

\begin{tabular}{lc}
\hline \multicolumn{1}{c}{ Item } & Value \\
\hline Modulus of elasticity $(\mathrm{GPa})$ & 45 \\
Poisson's ratio & 0.35 \\
Yield strength $(0.2 \%)(\mathrm{MPa})$ & 268.89 \\
Ultimate tensile strength $(\mathrm{MPa})$ & 344.74 \\
Plane stress fracture toughness, $K_{\mathrm{C}}\left(\mathrm{MPa} \cdot \mathrm{mm}^{1 / 2}\right)$ & 972.96 \\
Plane strain fracture toughness, $K_{\mathrm{IC}}\left(\mathrm{MPa} \cdot \mathrm{mm}^{1 / 2}\right)$ & 694.97 \\
Crack growth rate coefficient, $C$ & $7.96 \times 10^{-10}$ \\
NASGRO $n$ exponent, $n$ & 2.58 \\
NASGRO $p$ coefficient, $p$ & 0.25 \\
NASGRO $q$ coefficient, $q$ & 0.25 \\
Threshold SIF at $R=0, \Delta K_{\mathrm{th}}\left(\mathrm{MPa} \cdot \mathrm{mm}^{1 / 2}\right)$ & 48.65 \\
Plane stress/strain constraint factor, $\alpha$ & 1.5 \\
Ratio of the peak stress to the material flow & 0.3 \\
stress in a stress cycle, $S_{\max } / S_{0}$ & \\
\hline
\end{tabular}

and the polynomial coefficients are defined as (Newman et al., 1994):

$$
\begin{gathered}
A_{0}=\left(0.825-0.34 \alpha+0.05 \alpha^{2}\right)\left\{\cos \left[\frac{\pi}{2}\left(\frac{S_{\max }}{S_{0}}\right)\right]\right\}^{1 / \alpha}, \\
A_{1}=(0.415-0.071 \alpha) S_{\max } / S_{0}, \\
A_{2}=1-A_{0}-A_{1}-A_{3}, \\
A_{3}=2 A_{0}+A_{1}-1,
\end{gathered}
$$

where $\alpha$ is the plane stress/strain constraint factor, and $S_{\max } / S_{0}$ is the ratio of the peak stress $\left(S_{\max }\right)$ to the material flow stress $\left(S_{0}\right)$ in a stress cycle. The constants $\alpha$ and $S_{\max } / S_{0}$ are available as the fitting constants (BEASY, 2013).

\subsection{Boundary element model}

Linear quadratic elements (485 elements) were used to discretize the entire surfaces of the model as depicted in Fig. 2. To improve the accuracy of the stress and strain evaluations, the mesh size refinement of around $0.3 \mathrm{~mm}$ in the vicinity of the notch root was made. A uniform tensile stress of $30 \mathrm{MPa}$ was applied to either end of the model, and a fixed-displacement boundary condition in $x, y$, and $z$ directions was applied to another end. An initial elliptical surface crack was introduced on the notch root. The crack geometries are set to have a crack depth $a=0.5 \mathrm{~mm}$ and the crack aspect ratios $a / c=0.5,1$, and 2 . Fatigue crack simulations with a constant amplitude loading $R=0$ were carried out.

\section{Results and discussion}

To demonstrate the accuracy of the results obtained by using BEASY (BEASY, 2013), a comparison of the SIFs for a semi-elliptical surface crack in a smooth round bar under a tensile load (70 MPa) with those of the Raju-Newman solution (Raju and Newman, 1986) was made and plotted in Fig. 3a. The diameter of the smooth round bar $D$ is $10 \mathrm{~mm}$, the crack depth $a$ is $2 \mathrm{~mm}$, and the crack length $c$ is $2 \mathrm{~mm}$. The stress intensity factor $K_{0}$ shown in Fig. 3a is defined as

$$
K_{0}=\sigma \sqrt{\pi a},
$$


where $\sigma$ is the applied remote tension stress. It can be seen from Fig. 3a that the results are shown to be in good agreement. The largest difference is found at the mid-point of the crack front and is within $8 \%$. BEASY basically uses the dual boundary element method (DBEM) (Mi and Aliabadi, 1992) for 3D crack analysis. The axial stress contour around the crack tip and the mesh refinement generated using BEASY are shown in Fig. $3 b$.

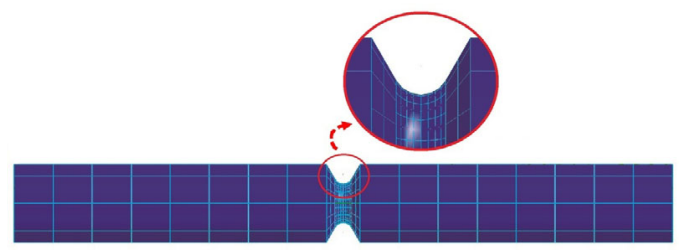

Fig. 2 Meshed V-shaped notched model
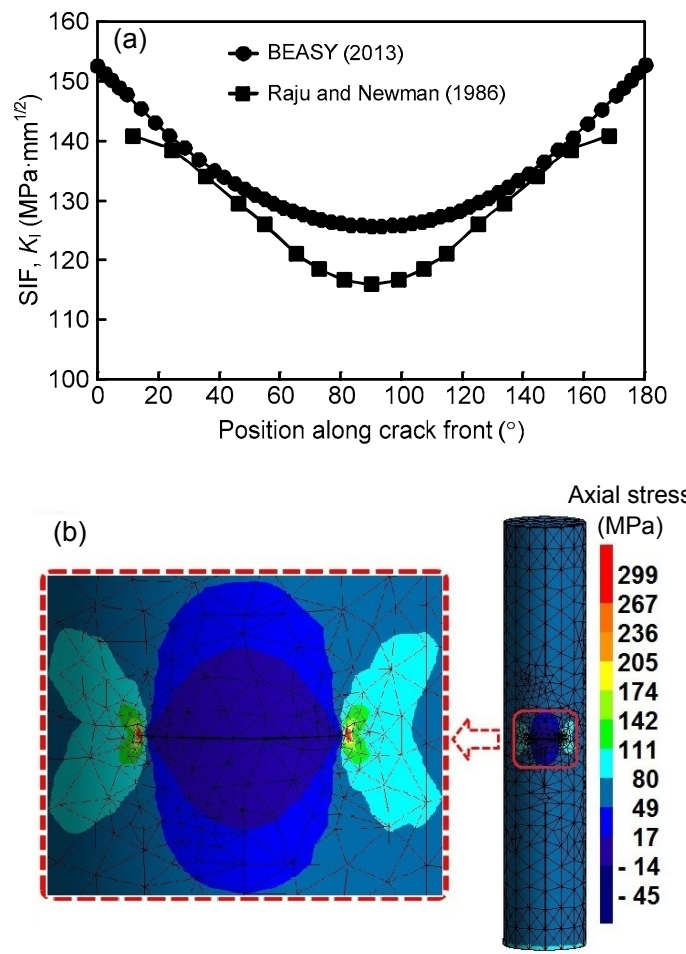

Fig. 3 Comparison of the SIFs for longitudinal semielliptical surface crack on a solid cylinder obtained by BEASY (2013) and Raju and Newman (1986) (a) and the corresponding axial stresses around the crack region (b)

It can also be seen from Figs. 4 and 5 that the axial stress contours for the initial and final increments around the crack fronts and the final crack opening modes can be identified. For a given crack depth $a$, the axial stresses for cracks with $a / c \neq 1$ are shown to be larger than those for $a / c=1$. However, a greater axial stress around the crack front does not necessarily result in a higher SIF.

The SIF values are largely dependent on the applied remote stress and geometry factors. Figs. 4 and 5 also show highly stressed zones around the notch root surface, causing the dislocations' shielding stress. The shielding effect leads to the maximum elastic stress shifting away from the notch root surface as a result of a condition where the regions around the crack front would physically experience plastic deformation.

The normalized SIFs $K_{\mathrm{I}} / K_{0}$ along the crack front for three different crack aspect ratios $(a / c)$ and two different notch radii $r$ of the selected increments during fatigue crack growths are presented in Fig. 6 (p.878). The mid-point of the elliptical crack front is defined as the point 0.5 of the $x$-axis, while the surface points of the crack front are denoted by the points 0 and 1 . The maximum and minimum normalized SIFs along the crack front at each increment during the crack propagation are found at the crossed surface points and the mid-point, respectively. As expected, for a given crack aspect ratio, more fatigue loading cycles going to failure are seen in the blunt notch model compared to those of the sharp notch model. In all cases, the largest SIFs are found at the surface points.

At the initial stage (increment 0), the SIFs along the crack front for $a / c=0.5$ are shown to have slightly different values (Fig. 6). Meanwhile, the differences in the SIF values along the crack front for the larger crack aspect ratios, i.e., $a / c$ of 1 and 2, are noticeably larger as evidenced by the SIFs patterns which form a U-shaped curve. The SIF patterns along the crack front for the larger crack aspect ratios $a / c$ tend to form flat-shaped curves in the first few increments and then appear to form U-shaped curves in the following increments. The shape evolution of the SIF patterns at the crack fronts for $a / c=1$ and 2 are shown to be different from those at the smaller crack aspect ratio $(a / c=0.5)$, which immediately forms U-shaped curves until fracture. It may be estimated from Table 2 (p.879) that the unstable crack extensions during crack growth are observed when the crack aspect ratio $a / c$ evolves to be between 0.6 and 0.7 . 

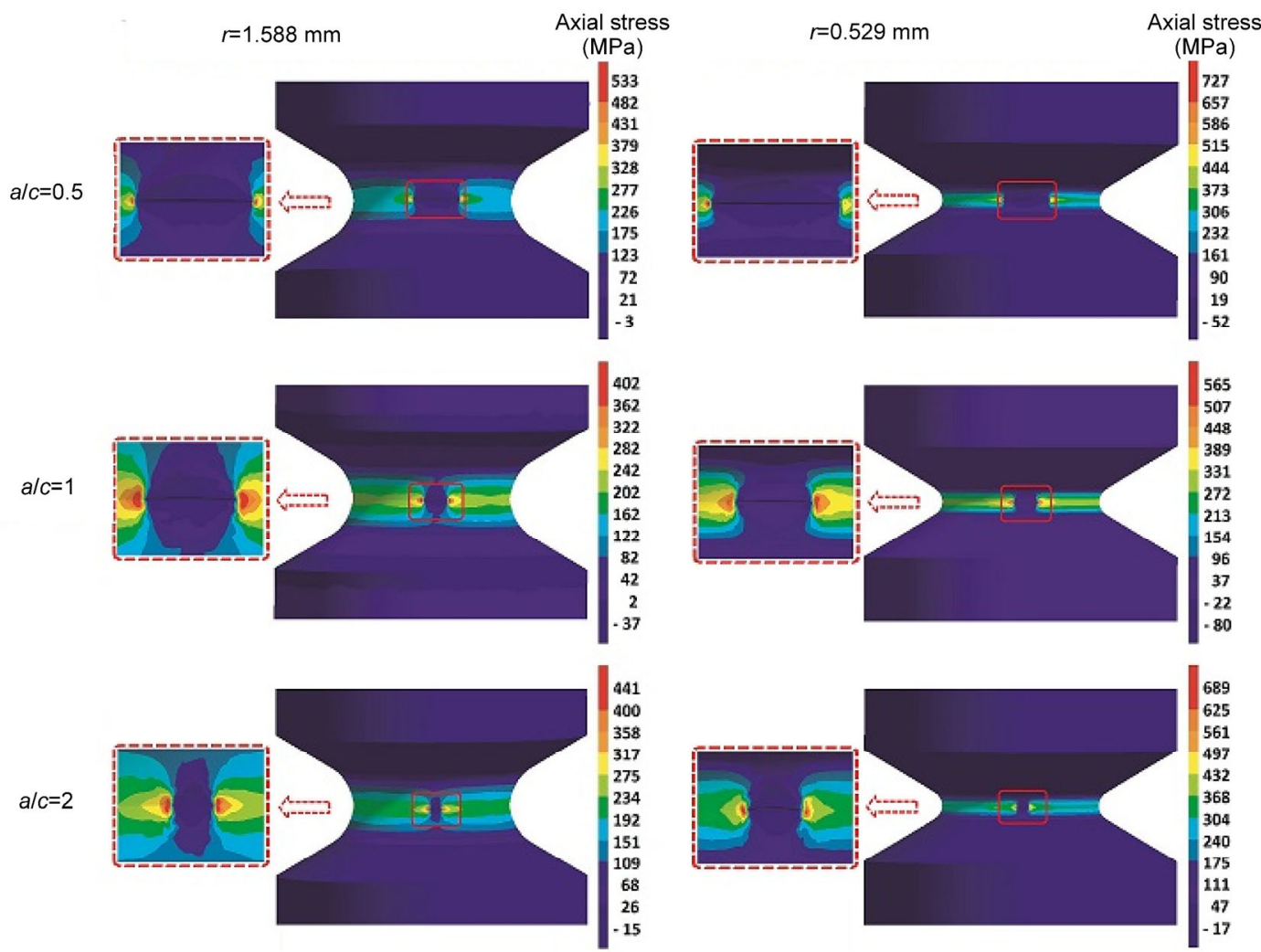

Fig. 4 Axial stress contours at around the surface crack at the initial increment
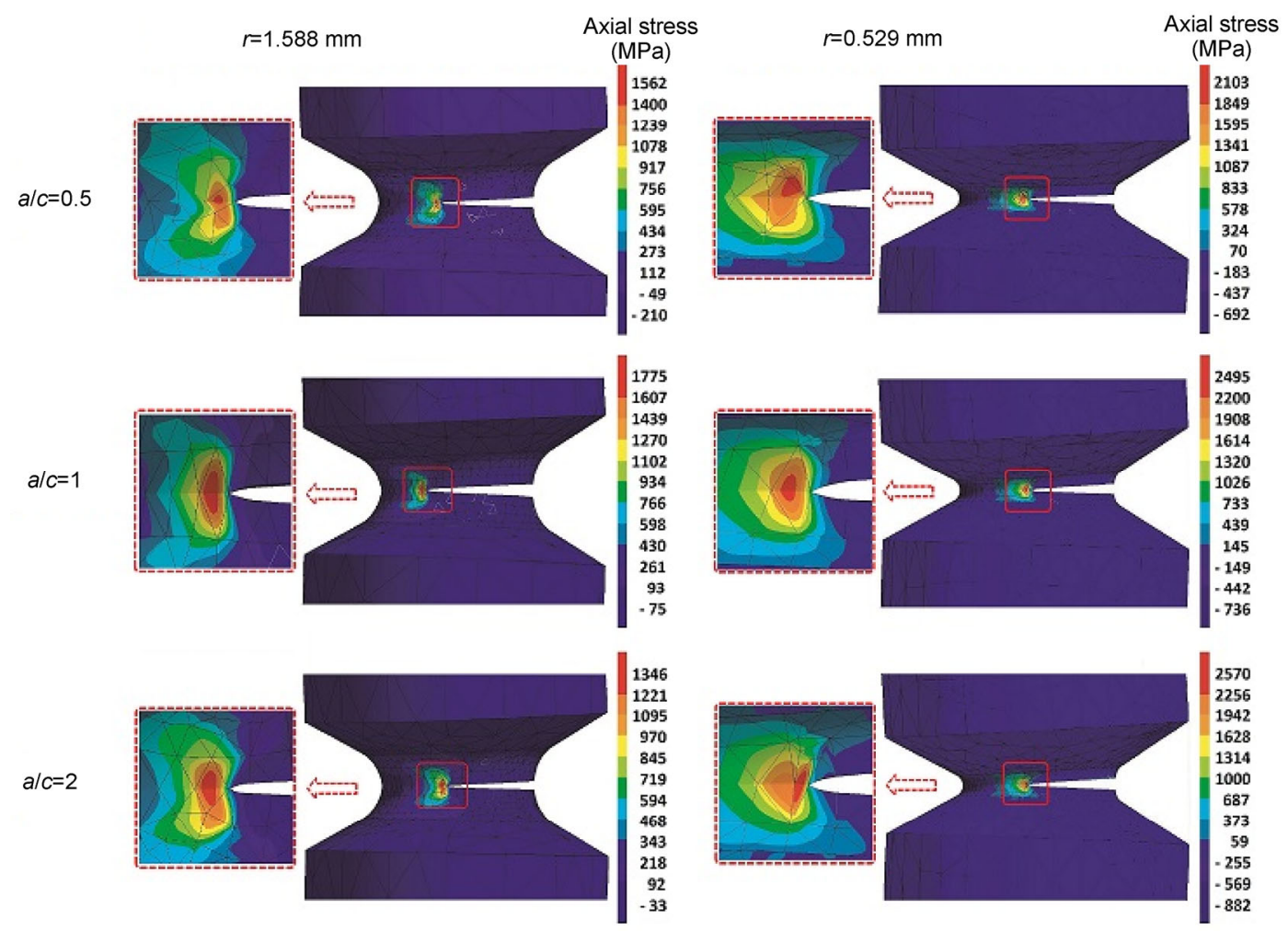

Fig. 5 Axial stress contours at around the surface crack at the final increment 

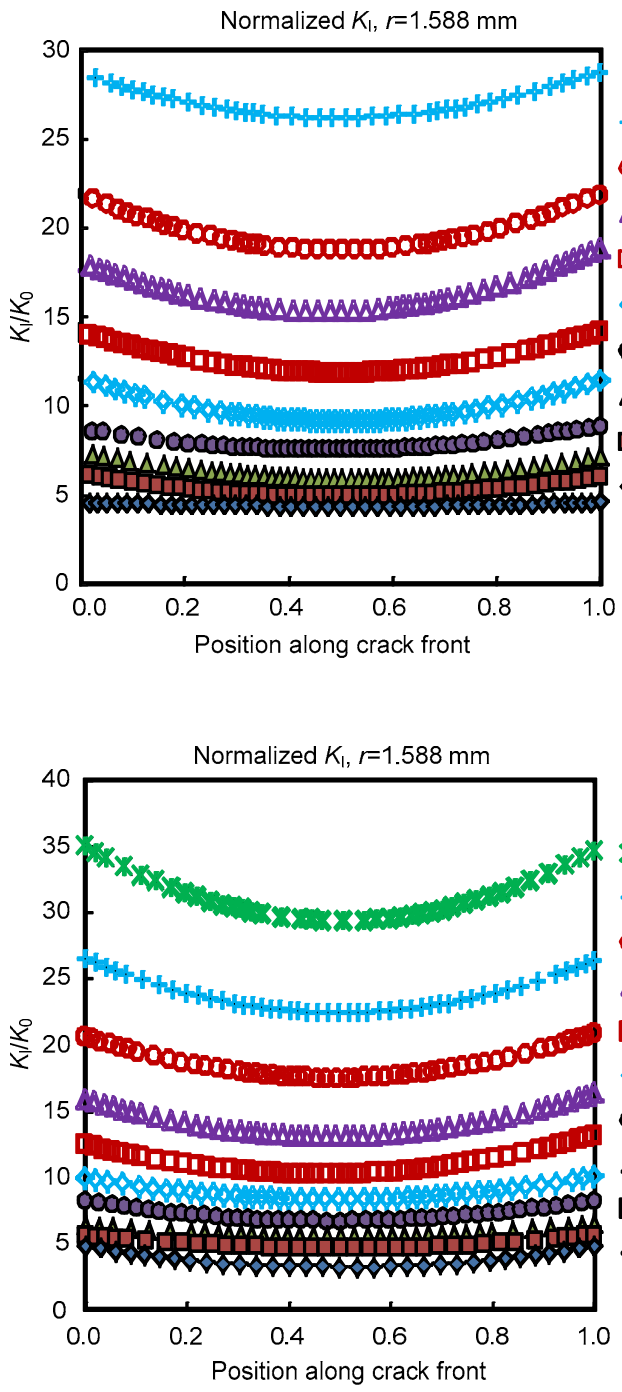

(a)

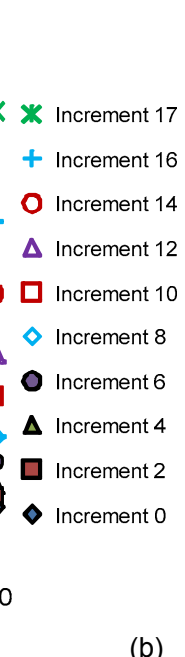

(b)

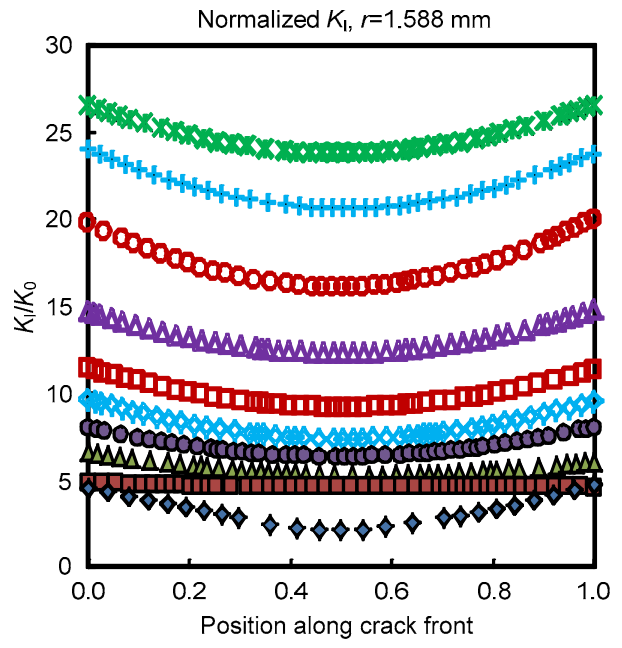

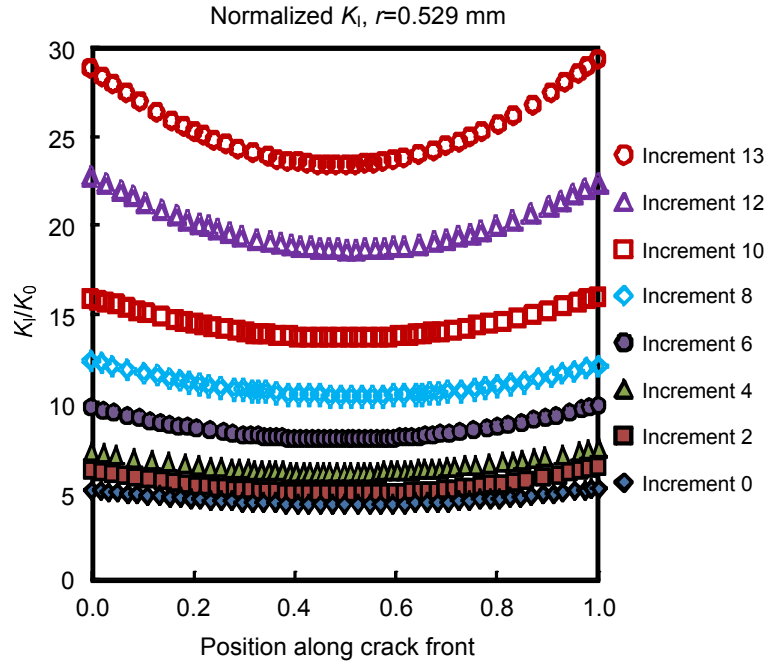
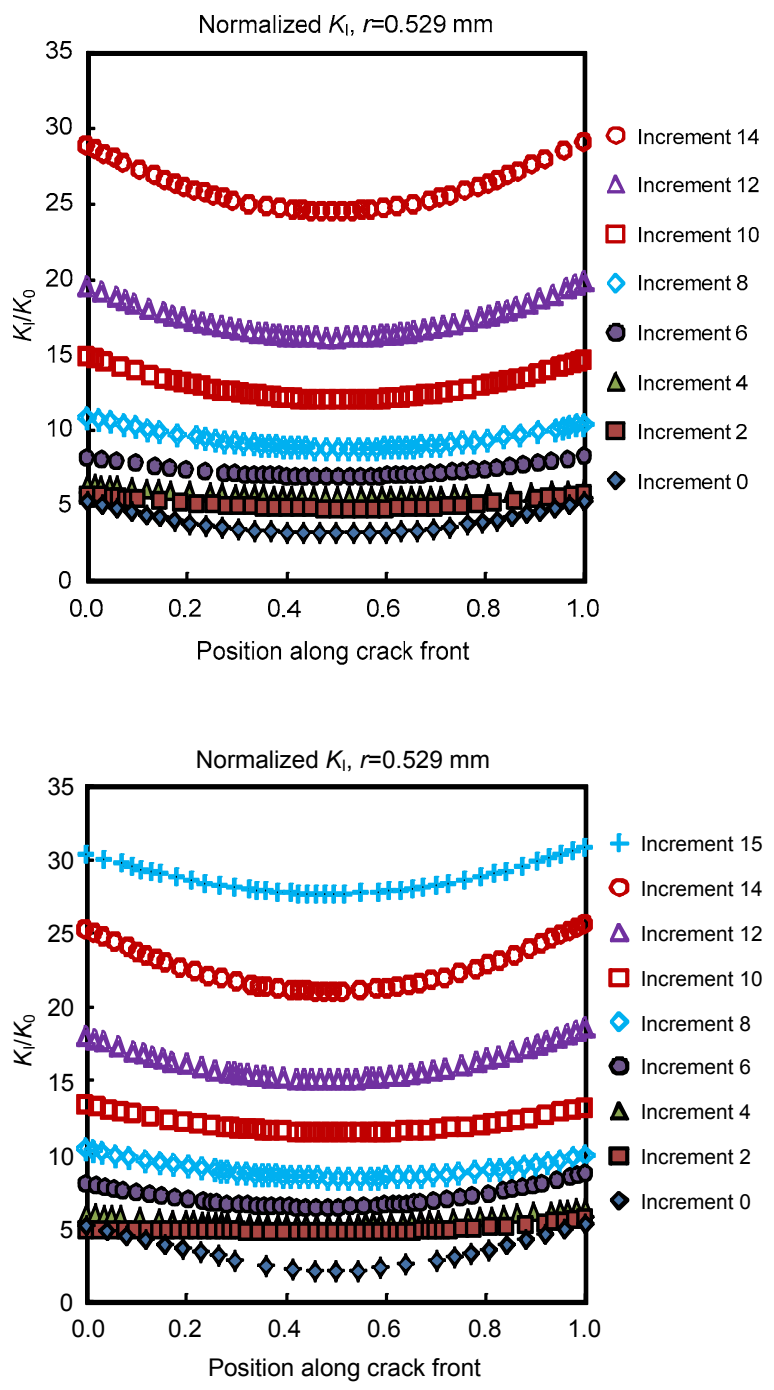

Fig. 6 Normalized SIFs for $a=0.5 \mathrm{~mm}, c=1 \mathrm{~mm}(\mathrm{a}) ; a=0.5 \mathrm{~mm}, c=0.5 \mathrm{~mm}(\mathrm{~b})$; and $a=0.5 \mathrm{~mm}, c=0.25 \mathrm{~mm}$ (c) 
Table 2 Crack geometries during fatigue crack growths

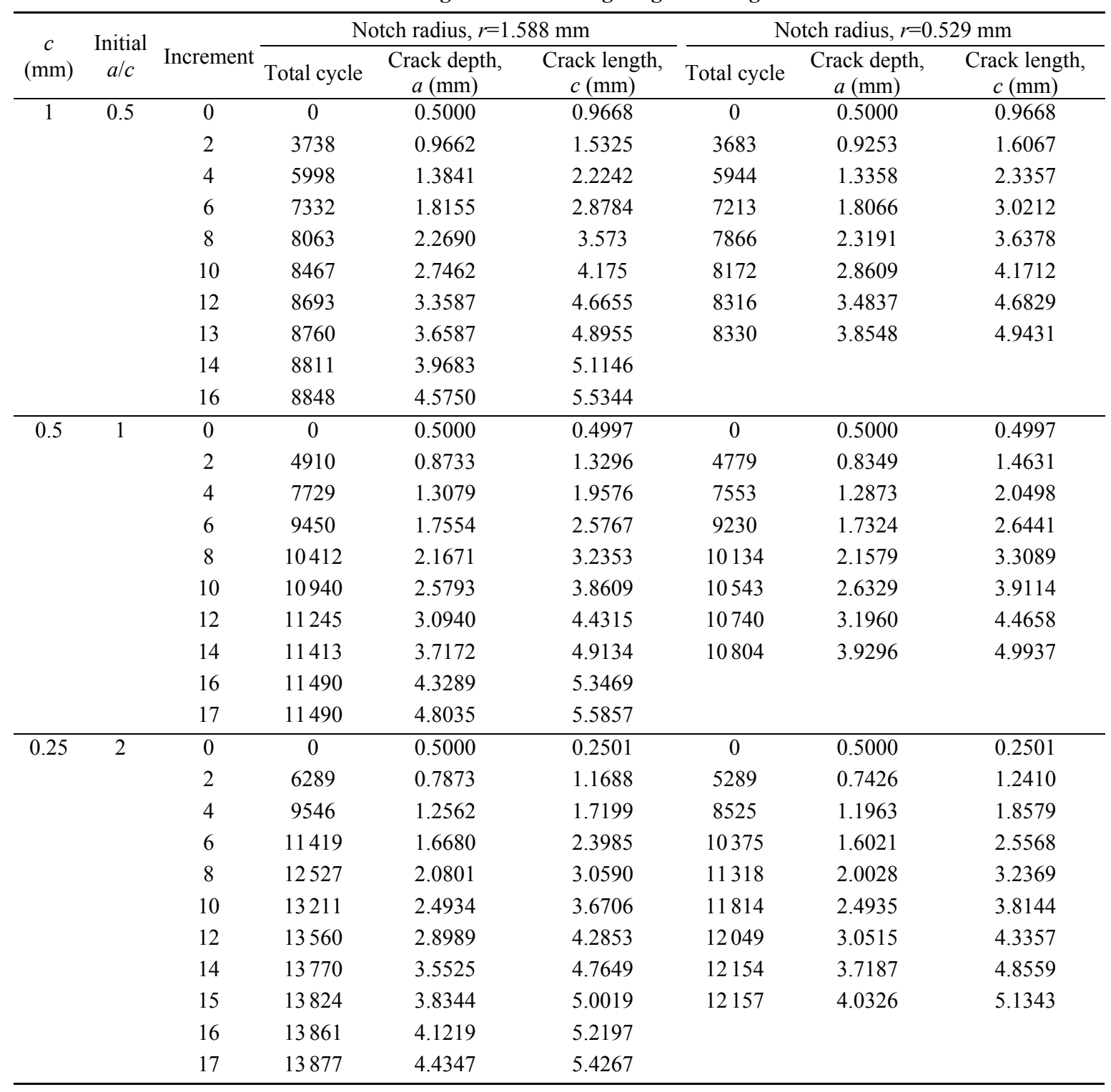

The crack shape evolutions for three different crack aspect ratios and two different notch radii are depicted in Figs. 7-12 (p.880-881). At the initial increment of the crack growth, the crack surfaces form an almond shape. Then, in the following increments, the shapes of the cracks evolve to form a nearly straight line at the crack front. It can also be observed from Figs. 7-12 that unstable crack growth is observed after the crack front has formed a straight shape. A careful consideration should be taken if the cylinder contains a defect like a 'shallow surface crack' with a straight crack front shape or with a smaller crack aspect ratio. Previous studies on the crack shape evolutions of a surface crack in smooth and notched cylinders have been reported (Carpinteri, 1993; Carpinteri and Brighenti, 1996; Lin and Smith, 1998; Carpinteri et al., 2006; 2013). They used linear Paris's equation for the crack growth simulations. Paris's equation does not consider the effect of crack closure during the crack growth, resulting in very conservative estimations and much shorter fatigue lives. Figs. 7-12 also show that the size of the initial crack aspect ratio would have a significant influence on the crack shape evolution during the crack growth.

Fig. 13a (p.881) shows that a smaller crack aspect ratio clearly leads to a shorter fatigue life. The 


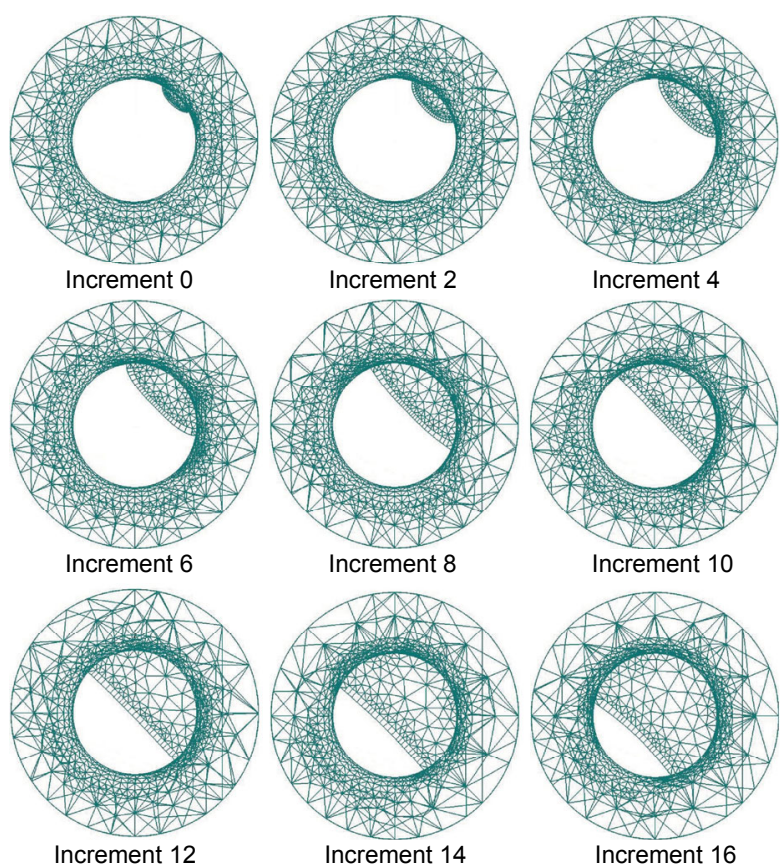

Fig. 7 Crack shape evolutions for $a / c=0.5$ and $r=1.558 \mathrm{~mm}$

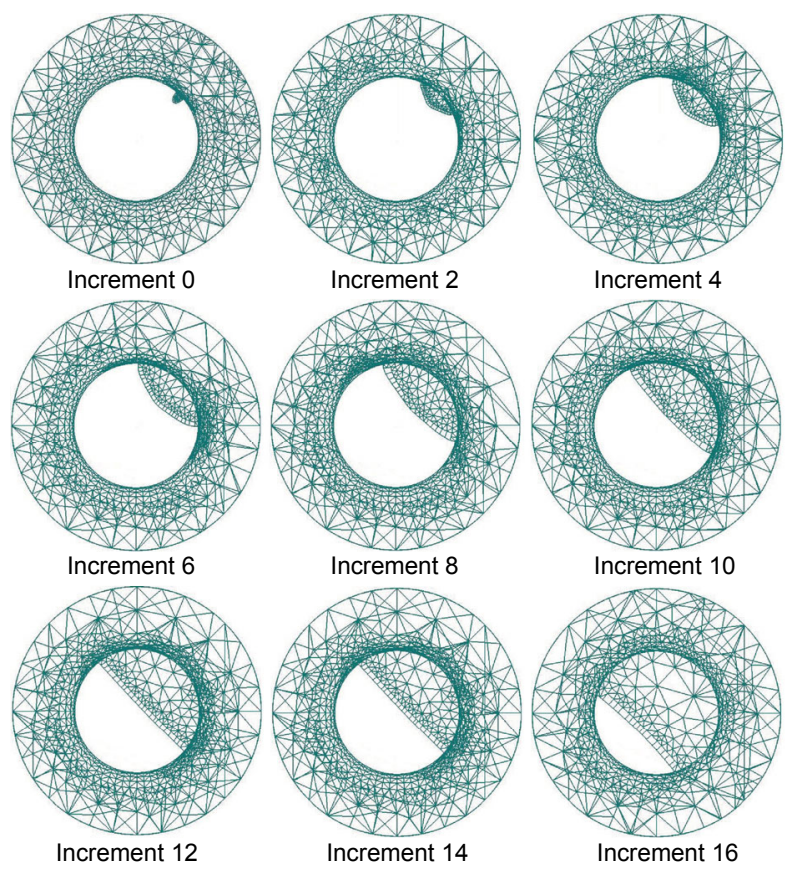

Fig. 9 Crack shape evolutions for $a / c=2$ and $r=1.558 \mathrm{~mm}$

effect of the crack aspect ratio on the fatigue life is shown to be more significant than the notch radius. Unstable crack growth is expected when the corresponding stress intensity factor $K_{\mathrm{I}}$ approaches the plane strain fracture toughness. It can be seen from

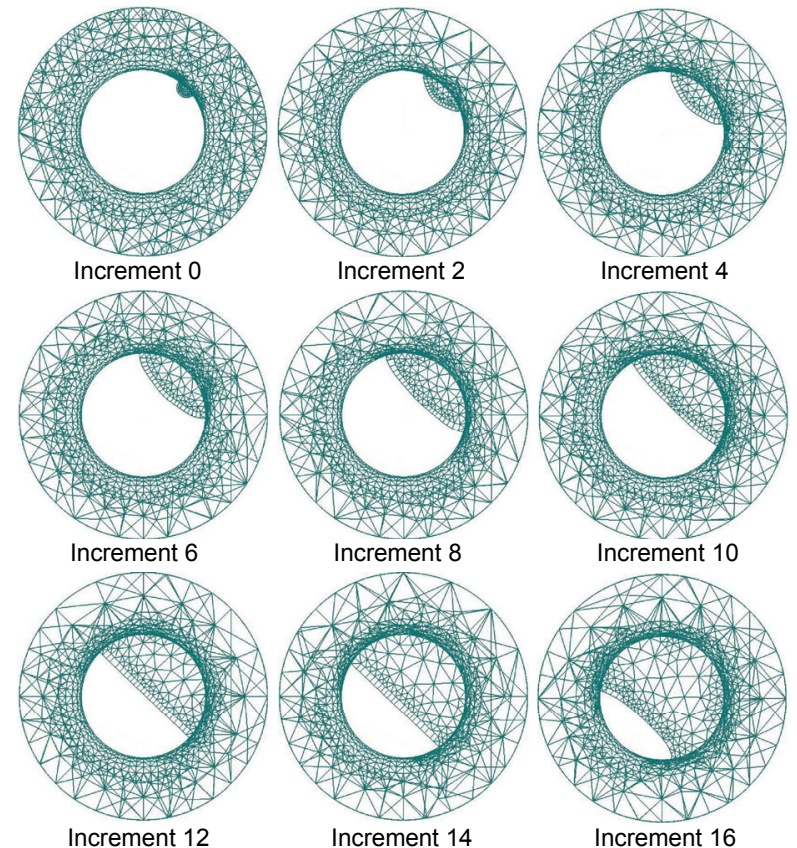

Fig. 8 Crack shape evolutions for $a / c=1$ and $r=1.558 \mathrm{~mm}$
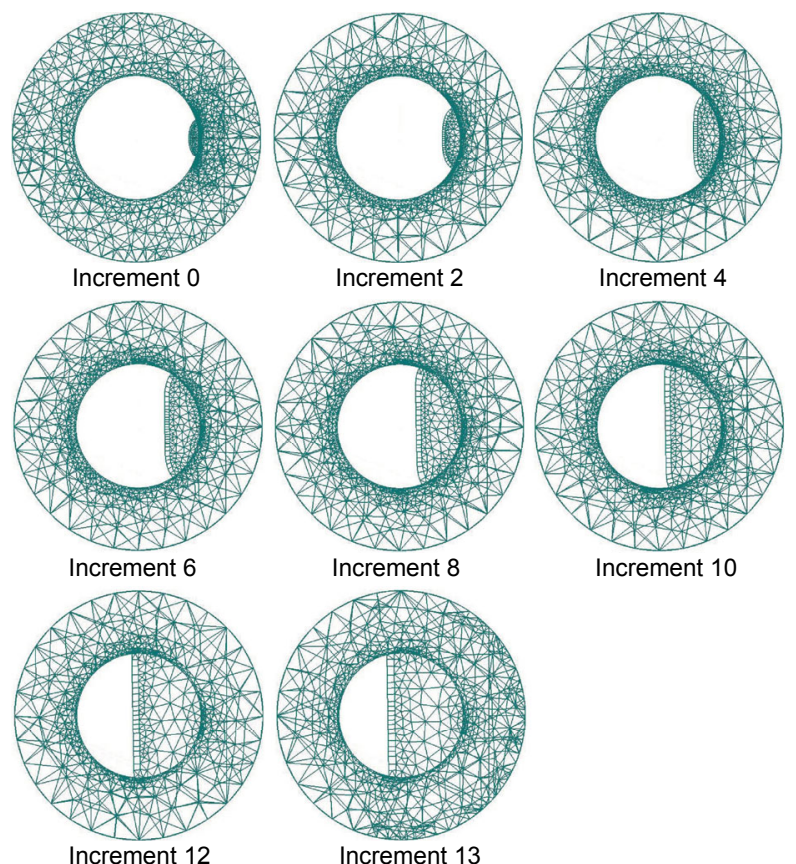

Fig. 10 Crack shape evolutions for $a / c=0.5$ and $r=0.529 \mathrm{~mm}$

Fig. 13b that unstable crack growths begin to happen when the SIF of the cracks is about $400 \mathrm{MPa} \cdot \mathrm{mm}^{1 / 2}$ (see Table 1 for the plane strain fracture toughness). The specimens fail when the SIFs attain the plane stress fracture toughness. 


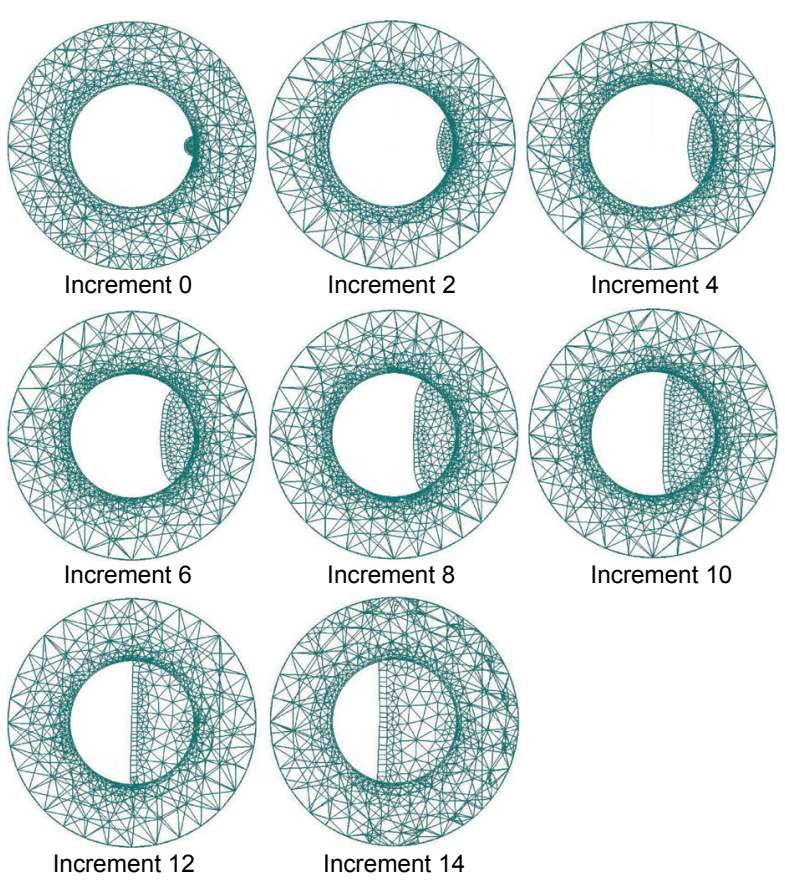

Fig. 11 Crack shape evolutions for $a / c=1$ and $r=0.529 \mathrm{~mm}$
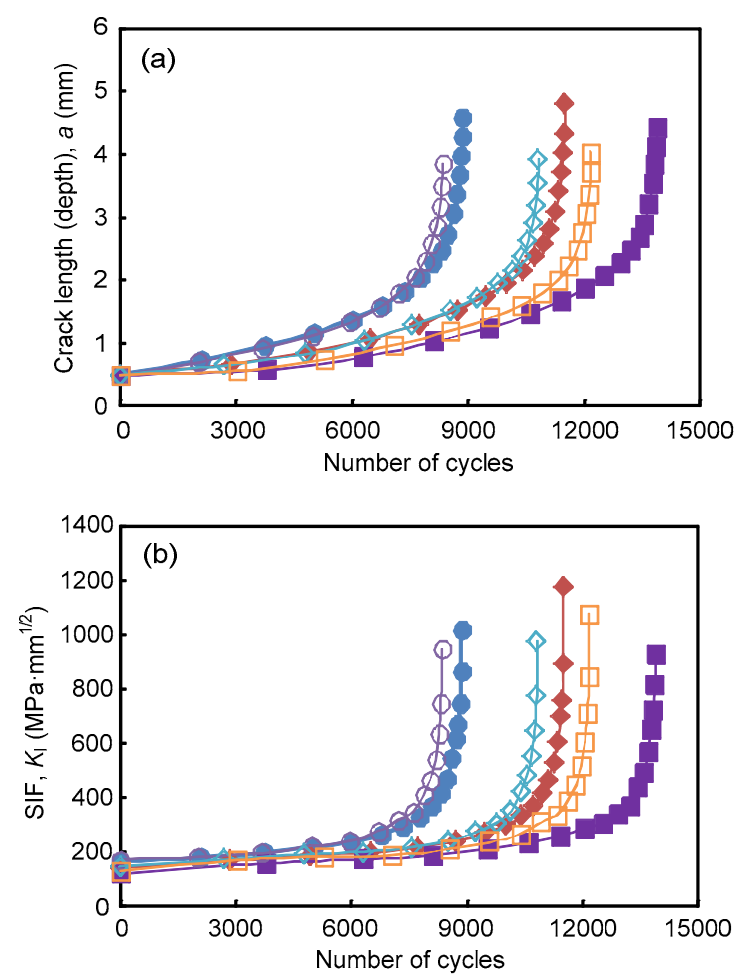

Fig. 13 Fatigue life versus crack length (depth), $a$ (a) and the SIFs, $K_{I}(b)$

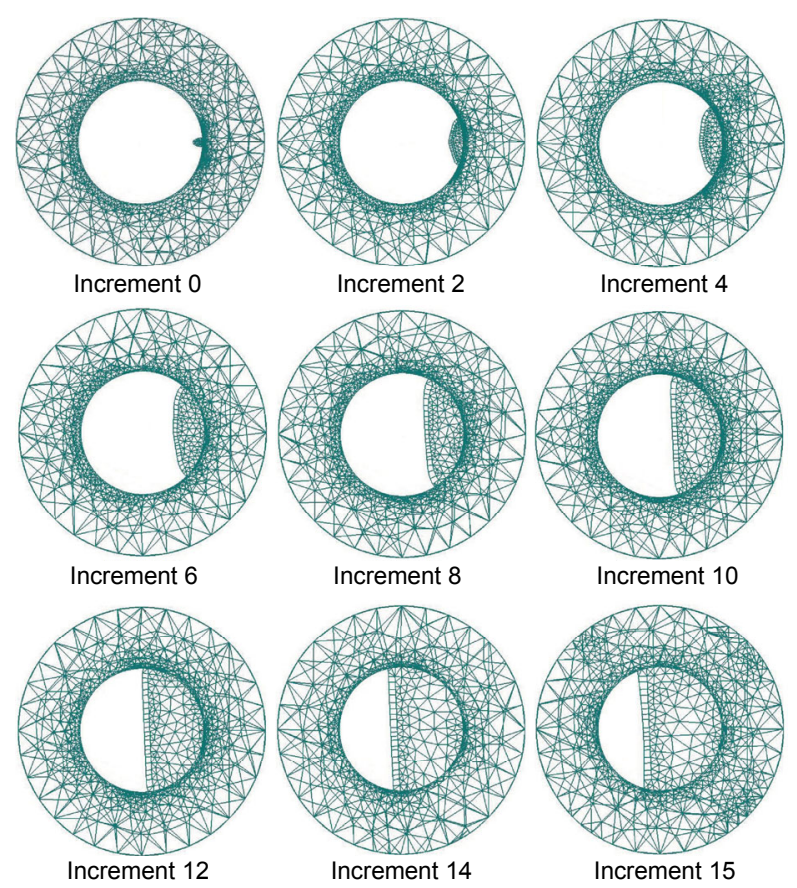

Fig. 12 Crack shape evolutions for $a / c=2$ and $r=0.529 \mathrm{~mm}$

\section{Conclusions}

Fatigue growths of a semi-elliptical surface crack in a V-shaped notched round bar subjected to uniform cyclic tension have been analyzed. A few statements are presented as follows:

1. The size of the initial crack aspect ratio has significant influence on the crack shape evolution during crack growth.

2. The effect of the crack aspect ratio on fatigue life is more significant than the notch radius.

3. Unstable crack growth was observed when the crack front had evolved to form a straight shape.

4. For a given crack depth, smaller crack aspect ratios lead to shorter fatigue lives.

5. The unstable crack extension during the crack growth was observed when the crack aspect ratio $a / c$ evolved to be between 0.6 and 0.7 .

\section{References}

BEASY, 2013. BEASY 10 Release 14.0012. Ashurst Lodge, Ashurst, Southampton SO40 7AA, UK.

Carpinteri, A., 1993. Shape change of surface cracks in round bars under cyclic axial loading. International Journal of Fatigue, 15(1):21-26. [doi:10.1016/0142-1123(93)90072-X] Carpinteri, A., Brighenti, R., 1996. Part-through cracks in 
round bars under cyclic combined axial and bending loading. International Journal of Fatigue, 18(1):33-39. [doi:10.1016/0142-1123(95)00076-3]

Carpinteri, A., Brighenti, R., Vantadori, S., 2006. Surface cracks in notched round bars under cyclic tension and bending. International Journal of Fatigue, 28(3):251-260. [doi:10.1016/j.ijfatigue.2005.05.006]

Carpinteri, A., Ronchei, C., Vantadori, S., 2013. Stress intensity factors and fatigue growth of surface cracks in notched shells and round bars: two decades of research work. Fatigue \& Fracture of Engineering Materials \& Structures, 36(11):1164-1177. [doi:10.1111/ffe.12092]

Guo, W., Shen, H., Li, H., 2003. Stress intensity factors for elliptical surface cracks in round bars with different stress concentration coefficient. International Journal of Fatigue, 25(8):733-741. [doi:10.1016/S0142-1123(03)00050-1]

Lin, X.B., Smith, R.A., 1998. Fatigue growth simulation for cracks in notched and unnotched round bars. International Journal of Mechanical Science, 40(5):405-419. [doi:10.1016/S0020-7403(97)00088-X]

Lin, X.B., Smith, R.A., 1999. Shape evolution of surface cracks in fatigued round bars with a semi-circular circumferential notch. International Journal of Fatigue, 21(9):965-973. [doi:10.1016/S0142-1123(98)00053-X]

Mi, Y., Aliabadi, M.H., 1992. Dual boundary element method for three-dimensional fracture mechanics analysis. Engineering Analysis with Boundary Elements, 10(2): 161-171. [doi:10.1016/0955-7997(92)90047-B]

Newman, J.C.Jr., Forman, R.G., DeKoning, A.U., et al., 1994. Fatigue Crack Growth Computer Program NASA/ FLAGRO Version 2.0. Report JSC-22267A, National Aeronautics and Space Administration, USA.

Raju, I.S., Newman, J.C.Jr., 1986. Stress-intensity factors for circumferential surface cracks in pipes and rods under tension and bending loads. ASTM Special Technical Publication, 905:789-805.

Shih, Y.S., Chen, J.J., 2002. The stress intensity factor study of an elliptical cracked shaft. Nuclear Engineering and Design, 214(1-2):137-145. [doi:10.1016/S0029-5493(02) 00022-5]

Shin, C.S., Cai, C.Q., 2004. Experimental and finite element analyses on stress intensity factors of an elliptical surface crack in a circular shaft under tension and bending. International Journal of Fracture, 129(3):239-264. [doi:10. 1023/B:FRAC.0000047784.23236.7d]

Zeng, Z., Fatemi, A., 2001. Elasto-plastic stress and strain behavior at notch roots under monotonic and cyclic loadings. The Journal of Strain Analysis for Engineering Design, 36(3):287-300. [doi:10.1243/0309324011514476]

\section{中文枚要:}

\section{本文题目: 反复张力下 $V$ 形切口圆条的表面裂纹的疲劳扩展}

Fatigue growth of a surface crack in a V-shaped notched round bar under cyclic tension

研究目的: 在相同的反复张力下, 研究 $\mathrm{V}$ 形切口圆条表面裂纹的疲劳扩展规律。

研究方法：1. 构建 $\mathrm{V}$ 形切口圆条模型（图 1），基于线性二次元将模型表面离散成一个个网格点（图 2）; 2. 以 AZ-6A-T5 镁合金为例，利用 $J$ 积分计算应力强度因数，利用 NASGRO 裂纹增长率模拟裂 纹的疲劳扩展; 3. 通过研究不同的裂纹纵横比和对应的应力强度因数之间的相关性来研究裂纹 的扩展。

重要结论: 1. 在裂纹扩展时裂纹纵横比的初始值对断裂形状的发展有重要影响; 2. 裂纹纵横比对瘦劳负 荷寿命的作用比缺口半径更加明显；3. 当裂纹前缘演变成一条直线形时可观察到不稳定的裂 纹扩展; 4. 裂纹深度一定时, 断裂纵横比越小, 疲劳负荷寿命越短; 5. 当裂纹纵横比为 $0.6-0.7$ 时, 出现了不稳定的裂纹扩展。

关键词组: 疲劳裂纹扩展; 裂纹纵横比; 边界元法; 应力强度因数 